\title{
BINDING OF SPERMATOZOA WITH SURFACE ACTIVE SPIN LABELS
}

\author{
J. C. HSIA,* L. H. PIETTE AND R. W. NOYES \\ Department of Biochemistry and Biophysics and Department of Anatomy, \\ School of Medicine, University of Hawaii, Honolulu, Hawaii 96822
}

(Received 24th March 1969)

Success in studying the rate of flow of spermatozoa through the female reproductive tract in vivo will require a sperm-labelling method better than those at present available. Radiophosphorous labelling in vivo (Ortavant, 1954), and radio-active amino acid labelling in vitro (Bhargava, 1957) do not yield specific activities high enough for detection in vivo. Fluorescence labelling cannot be detected in vivo (Ericsson, 1967). Partial success has been obtained by binding spermatozoa to ${ }^{131}$ I-labelled anti-sperm antibody in vitro, but this label is slowly lost from the spermatozoa in the female tract (Noyes, 1968, 1969). A surface active label has been designed which can intercalate itself between the lipid bilayers or the lipoprotein fraction of plasma membranes (Hsia \& Piette, unpublished). The present report is a preliminary account of the adaptation of this labelling method to rabbit spermatozoa in vitro.

Lauric, myristic and stearic fatty acid spin labels with the following general structure

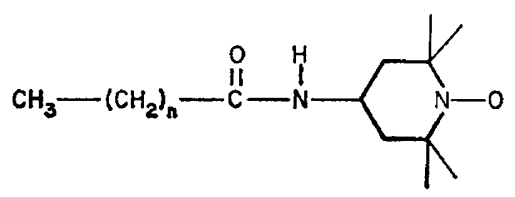

where $\mathrm{n}=11,14,16$ were prepared as follows: Equal molar amounts of fatty acid, and 1-oxyl-2,2,6,6-tetramethyl-4-amino piperidine and decyclohexylcarbodiimide were allowed to react in ethyl acetate at room temperature for $12 \mathrm{hr}$. Solvent was evaporated under vacuum. Residues were chromatographed on silicic acid columns and eluted with chloroform. The fast-moving reddish band was collected and recrystallized from ether-hexane.

Two surface active compounds were used in the present experir: ${ }^{-n}$. Compound I is $\mathrm{N}$-(1-oxy-2,2,6,6-tetramethyl-4-piperidinyl)-myristate, anc II is the stearate analogue of the same compound.

Since their reactions are very similar, only Compound I will be further discussed. The long chain, hydrophobic fatty acid is attached by amide linkage to a paramagnetic reporter molecule (spin label) in which the free radical nitroxide is sterically protected by four methyl groups. These compounds are

* Present address: Division of Biochemistry and Molecular Biology, National Research Council of Canada, Ottawa. 
insoluble in water but they are readily dissolved by lauryl sulphate micellular solutions in an ethyl alcohol carrier. A typical electron spin resonance (ESR) spectrum is shown in Text-fig. 1. The sharp triplet ESR spectrum is characteristic of a rapidly tumbling micellular structure (Waggoner, Griffith \& Christensen, 1967).

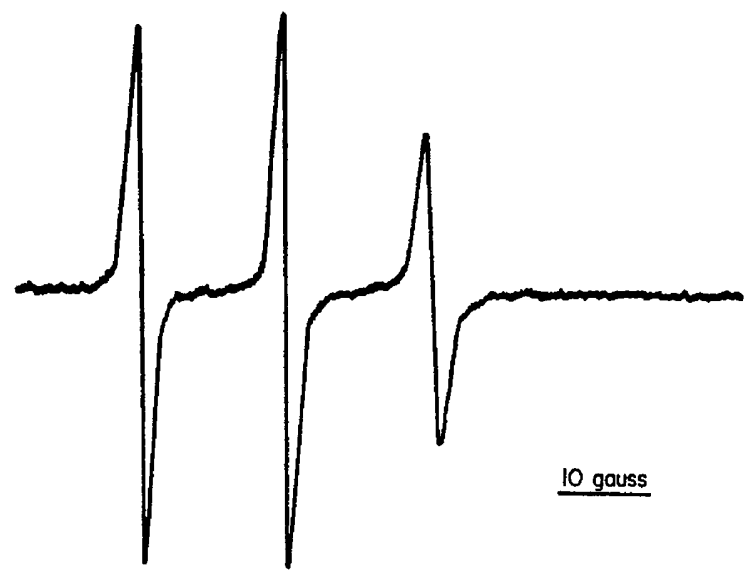

TexT-Fig. 1. Electron spin resonance spectrum of myristate spin label in the absence of spermatozoa. The spin label concentration is $1 \times 10^{-4} \mathrm{M}$ in $5 \%$ sodium lauryl sulphate in NJ-2 medium. The magnetic field increases from left to right, the field scan magnitude is indicated by the 10 gauss marker. The separation between crossover points of the absorption lines is 15.7 gauss.

Rabbit semen was collected by means of an artificial vagina, centrifuged at $3100 \mathrm{rev} / \mathrm{min}$ for $10 \mathrm{~min}$ and the seminal plasma discarded. The spermatozoa were resuspended in NJ-2 medium (Norman, 1964) without antibiotics in a concentration of $10^{8}$ spermatozoa $/ \mathrm{ml}$. Ten to $50 \mu \mathrm{l}$ of a stock solution containing $10 \mathrm{~m}$-moles of Compound I in ethyl alcohol was added to $1 \mathrm{ml}$ of NJ-2 containing $10^{8}$ highly motile spermatozoa. Spectra of the resulting mixtures were taken, using a Varian E-3 ESR spectrometer.

Sperm labelling was instantaneous. The ESR spectrum (Text-fig. 2) indicated that the spin-labelled molecules were strongly immobilized, evidently as a result of intercalation in the sperm cell membranes. After $5 \mathrm{hr}$, there was no difference in sperm motility, as observed by light microscopy, between labelled and control samples. It is estimated that between $10^{9}$ and $10^{10}$ molecules of Compound I adhered to each spermatozoon. Repeated washing, centrifugation and dialysis did not reduce the sperm specific activity. Adding lauryl sulphate to the labelled spermatozoa (Text-fig. 2) resulted in an ESR spectrum identical to that of Text-fig. 1, indicating that the membrane of the spermatozoa had been solubilized to micellular structure (Waggoner, Griffith \& Christensen, 1967).

In summary, a new sperm label is reported with the following characteristics: it adheres rapidly and firmly to spermatozoa in vitro, it is non-toxic at levels of $10^{9}$ to $10^{10}$ molecules per spermatozoon, and its mobility relative to the sperm cell membrane can be measured by means of the ESR spectral configuration. 
Further studies are being undertaken to determine the binding strengths of these labels in vivo, to see if labelling is related in any way to sperm capacitation, to design an ESR sperm detector in vitro and to substitute ${ }^{14} \mathrm{C}$ into the fatty acid chain as an alternative means of detection.

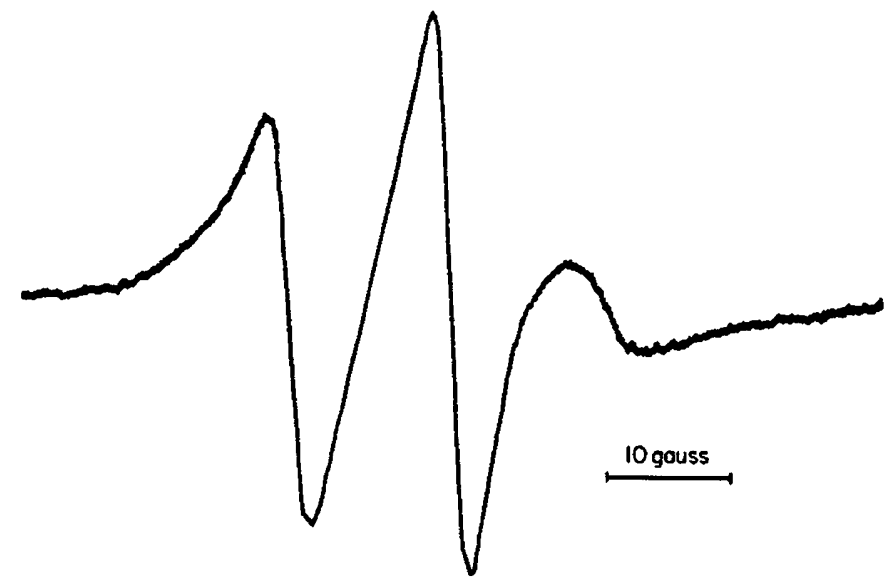

TEXT-FIG. 2. Electron spin resonance spectrum showing the results of binding of myristate spin-label to the spermatozoa. Spectrum was recorded using a different magnetic field scan as indicated by the 10 gauss marker. No loss of spin label is observed. The change in the spectrum reflects only a change in the spin-label mobilization.

\section{REFERENCES}

Bhargava, P. M. (1957) Incorporation of radioactive amino acids in the proteins of bull spermatozoa. Nature, Lond. 179, 1120.

Ericsson, R. J. (1967) Technology, physiology and morphology of spermatozoa capacitation. $\mathcal{J}$. Reprod. Fert. Suppl. 2, 65.

Norman, E. (1964) Further studies on the preservation of mammalian sperm at variable temperatures. Proc. Vth Int. Congr. Anim. Reprod. Artif. Insem., Trento. Vol. IV.

Noyes, R. W. (1968) ${ }^{131}$ I-antibody tagging of spermatozoa. (Abstract). Anat. Rec. 160, 488.

Noyes, R. W. (1969) Antibody binding of spermatozoa. Fert. Steril. 20, 43.

Ortavant, R. (1954) Détermination de la vitesse de transfert des spermatozoïdes dans l'épididyme de bélier à l'aide de ${ }^{32}$ P. C. r. Séanc. Soc. Biol. 148, 866.

Waggoner, A. S., Griffith, O. H. \& Christensen, C. R. (1967) Magnetic resonance of nitroxide probes in micelle-containing solutions. Proc. natn. Acad. Sci. U.S.A. 57, 1198. 